\title{
El Reto de Vincular a los Pequeños Productores de Papa con la Agroindustria
}

\author{
Thomas Bernet ${ }^{1}$ Martín Lara ${ }^{2}$, Pedro Urday ${ }^{3}$, André Devaux ${ }^{4}$
}

\begin{abstract}
Resumen
El aumento del consumo de papa procesada está permitiendo que la agricultura por contrato gane importancia. Los pequeños productores de papa podrían aprovechar esta modalidad para superar sus dificultades en la comercialización, accediendo a un mercado seguro con precios rentables y estables. No obstante, la literatura revisada y un caso específico de la Sierra Central del Perú demuestran que las empresas procesadoras de papas en tiras y hojuelas prefieren trabajar con los grandes productores, principalmente por razones de costos de transacción y calidad del producto. Los pequeños productores más bien son "una solución de emergencia", cuando no existe un número adecuado de productores grandes logrando abastecer la planta de procesamiento. En este sentido, el crecimiento rápido del consumo de papa procesada en América Latina constituye una buena oportunidad coyuntura! para los pequeños productores. Por falta temporal de suficientes proveedores de grandes volúmenes, ellos puedan aprovechar de este negocio a corto plazo mejorando su competitividad para formar asociaciones de productores. Posteriormente, estas asociaciones podrían reorientar su producción hacia nichos de mercados que "capitalicen" las ventajas reales de los pequeños productores que son: el seguimiento eficiente del cultivo y la mano de obra barata. El apoyo externo de parte de las instituciones de desarrollo debe tener un enfoque más empresarial en identificar e implementar actividades competitivas para pequeños productores. Por lo tanto, son esenciales capacidades en mercadeo y en liderazgo de procesos participativos para formar y consolidar asociaciones de productores exitosas en el mercado.
\end{abstract}

Palabras claves adicionales: $\quad$ Agroindustria, agricultura por contrato, asociaciones de productores, hojuelas de papa, pequeños productores, Perú.

1 Ph.D. Economista Agrícola y líder del subproyecto "Poscosecha de Papa", Centro Internacional de la Papa (CIP), Apartado 1558, Lima 12, Perú, (t.bernet@cgiar.org).

2 Agrónomo, investigador independiente, Huanchar, Concepción, Junín, Perú. (maroslala@ hotmail.com).

3 Economista, Director del Programa Rural de FOVIDA, Magdalena, Lima, Perú (purday@fovida.org.pe).

4 Ph.D. Agrónomo, Coordinador del proyecto regional Papa Andina, Centro Internacional de la Papa (CIP), Apartado 1558, Lima 12, Perú, (a.devaux@cgiar.org) 


\title{
The Challenge of Linking Small-Scale Potato Growers with Agro-Industry
}

\begin{abstract}
Summary
The increase in demand for processed potatoes implies that contract farming is gaining importance. To overcome their restrictions in commercialization, small potato farmers would considerably benefit from this working modality getting access to a secure market with profitable and stable prices. Indeed, literature revision and a specific case from the Peruvian Andes reveal that chip and French fries processing enterprises have a clear preference to work with large potato growers, basically because of transaction costs and product quality. Small farmers are rather an "emergency solution" when there are not enough large potato growers to supply the processing plant. In this sense, fast growing demand for processed potato products in Latin America provides a timely opportunity for small-scale potato farmers. Given the temporary lack of sufficient large potato suppliers they might take advantage of this market opportunity enhancing their competitiveness by forming producer associations, which later on can be reoriented towards market niches which "capitalize" the real advantages small farmers have: efficient crop supervision and cheap labor. External support from the side of development institutions should have a stronger entrepreneurial focus in the identification and implementation of competitive activities for small-scale farmers. Hence, capacities in marketing and leadership for participatory processes are essential to constitute and consolidate successful market-oriented farmer associations.
\end{abstract}

Additional Index words: $\quad$ Agro-industry, contract agriculture, producer associations, potato chips, small-scale producers, Perú.

\section{Introducción}

En las últimas décadas la producción de papa ha adquirido gran importancia en los países en desarrollo, donde prevalecen la pobreza y la mano de obra barata (14). En muchos de estos países el consumo de papa en fresco es alto debido al gran número de personas con bajos ingresos. A la vez, el consumo de papa industrial es relativamente bajo por la carencia de tecnología apropiada, el costo elevado de capital, impuestos y falta de 
volúmenes necesarios para abaratar los costos de procesamiento aprovechando las economías de escala. Es más bien el sector informal el que juega un rol primordial en el procesamiento, porque opera a costo más bajo, aunque con inferior calidad (13).

No obstante, el cambio de hábitos de consumo también es notorio en los países pobres, lo que ha originado un rápido crecimiento de los productos procesados, especialmente a base de papa. La causa principal de este cambio es el crecimiento sostenido de la población urbana, lo que trae un estilo de vida diferente en función de las nuevas modalidades de trabajo (separación del trabajo del hogar, participación de las mujeres en trabajos fuera de la casa, etc.) (22). Así, la demanda de papas fritas ha crecido debido a la expansión continua de las cadenas internacionales de comida rápida y de pollerías nacionales (6). En menor medida -pero también importantese está generando un aumento de la demanda de hojuelas de papa. Debido a que la papa en fresco es un producto inferior desde el punto de vista económico (cuyo consumo baja cuando aumentan los ingresos), en contraste con la papa procesada (cuyo consumo aumenta cuando aumentan los ingresos), se espera que la producción de papa procesada siga creciendo en forma similar a lo que ocurre en los países desarrollados (22).

El aumento de papa procesada tendrá un fuerte impacto sobre la producción y los productores de papa debido a que la industria exige una calidad específica de papa y un abastecimiento continuo para satisfacer a sus consumidores finales.

Desde un punto de vista socio-económico resulta relevante preguntarse si los pequeños y medianos productores de papa van a ser competitivos y capaces de aprovechar la oportunidad de trabajar con empresas que procesan papa. Este artículo pretende sintetizar las lecciones encontradas en la literatura sobre este tema y analizar un caso específico de la sierra central del Perú, donde una empresa procesadora, además de estar vinculada con los grandes productores, ha incorporado a pequeños y medianos productores de papa en su esquema de trabajo bajo contrato.

\section{Agricultura por Contrato}

\section{Definición y modalidades}

En general, se denomina agricultura por contrato a un acuerdo legal entre los agricultores y una empresa privada para sincronizar la oferta y la demanda de un cierto producto (8). Minot (18) distingue tres diferentes modalidades de contratos, que conllevan diferentes motivos de colaboración: (1) contratos que especifican condiciones de venta/compra del producto (precio, calidad estándar del producto y fecha de entrega), (2) contratos que especifican la provisión de insumos (créditos e insumos de producción) y (3) contratos que garantizan una capacitación adecuada para segurar un régimen especial de producción (producción orgánica, por ejemplo). 
La realidad demuestra que en la mayoría de casos los contratos efectuados entre productores y empresas consisten en una combinación de dichos componentes, dependiendo mucho del contexto específico en cada caso.

\section{Razones de colaboración entre empresas y agricultores}

Es importante resaltar que cualquier contrato entre una empresa y los agricultores es el resultado de una voluntad mutua de colaboración. En principio, un contrato conviene a ambas partes: el productor disminuye el riesgo de comercialización (logrando garantía de compra), mientras que la empresa asegura la obtención de su materia prima (logrando garantía de venta). Sin embargo, la decisión de implementar un sistema de producción por contrato siempre está en manos de la empresa. Esto, porque la empresa tiene otras opciones de conseguir su materia prima, sea (a) en el mercado mayorista o (b) produciéndola ella misma (4). En el segundo caso, la empresa logra una integración vertical, manejando toda la cadena productiva, desde la producción hasta la comercialización.

Una empresa sólo busca contratos con agricultores si esta opción es la más rentable y segura para la provisión de la materia prima que requiere. En otras palabras, la agricultura por contrato es solamente una opción interesante para una empresa cuando no existe un amplio mercado que provea el producto deseado y si la integración vertical de la empresa no es rentable o adecuada por razones políticas o financieras. En consecuencia, desde el punto de vista de una empresa, la concurrencia de tres factores favorecen la implementación de contratos: (1) escasez de oferta del producto requerido (ausencia del producto en el mercado mayorista por poca demanda nacional), (2) la producción del producto no requiere alta tecnología ni procesos sofisticados (sino tecnología común difundida entre los agricultores) y (3) los principales factores de producción son más baratos cuando son aportados por los agricultores.

En los países en desarrollo estos tres factores, por lo general, están presentes cuando se trata de productos no tradicionales que se cultivan para la exportación -como frutas y verduras-, los cuales son intensivos en términos de mano de obra pero no involucran alta especialización ni tecnologías sofisticadas. En contraste, en los países desarrollados, estos tres factores están presentes más bien en la producción de cultivos para la agroindustria, donde los contratos con los productores permiten planificar un abastecimiento adecuado de la planta de procesamiento con materia prima de alta calidad (8). Una gran ventaja para las empresas en los países desarrollados es que todos los productores tienen buen nivel de educación están familiarizados con la tecnología de producción y tienen un buen acceso a los factores de producción (información, maquinaria, capital, etc.) 
Desde el punto de vista de los agricultores, los contratos son interesantes porque ayudan a bajar el riesgo de comercialización del producto. Generalmente la empresa asegura la compra del producto a un precio preestablecido, que comúnmente está por encima del precio que se consigue en un mercado alternativo. Además, los productores suelen aprovechar la capacitación y la provisión de ciertos insumos que ayudan a aumentar la rentabilidad en otros cultivos.

\section{Riesgos y desventajas de los contratos}

A pesar de las ventajas que los contratos conllevan tanto para las empresas como para los productores, esta modalidad de colaboración también involucra ciertos riesgos. El problema más común es el riesgo de incumplimiento o distorsión del contrato por cualquiera de las partes $(11,21)$ que incluso es más grande en los países en desarrollo, donde el sistema legal es inestable y poco confiable y suelen predominar empresas con mucho poder de negociación (12). Por ser las únicas compradoras y por la falta de alternativas productivas de parte de los agricultores, estas empresas poderosas tienden a manipular aspectos del contrato (normas de calidad, precios, etc.) o modalidades del trabajo (control de calidad, atraso del pago, etc.) siempre y cuando la venta del producto final se reduzca o el precio de la materia prima suba debido al aumento de competencia por parte de otras empresas. Es exactamente por el poder de muchas empresas y su mal uso -lo cual implica contratos poco favorables para los agricultores (precios bajos, garantía reducida de compra, etc.)que la agricultura por contrato ha sido muy criticada sobre todo en África, donde las alternativas productivas son particularmente escasas y los productores prácticamente son forzados a trabajar con estas empresas poderosas para tener acceso al mercado (16).

Sin embargo, también los productores tienden a infringir los contratos si se presentan mejores alternativas. En especial en los países en desarrollo, donde los procesos legales son largos y costosos, el riesgo para una empresa de que "sus" agricultores desvíen parte de su cosecha o reorienten insumos y créditos hacia otros fines cuando hay otra manera de optimizar los ingresos es muy grande (Tabla 1). En este contexto, la experiencia demuestra que la única garantía de que el agricultor cumpla el contrato es cuando la colaboración con una empresa se percibe más beneficiosa que otras alternativas de producción a largo plazo (11). En ese momento, el proveedor no estará dispuesto a infringir el contrato por un beneficio a corto plazo que ponga en riesgo su colaboración con la empresa en el futuro. 
Tabla 1. Ventajas y desventajas de los contratos para las empresas privadas y los productores.

\section{Ventajas para la empresa}

Delegación del riesgo de producción a productores

Delegación del pago de salarios a productores

No-inmovilización de capital en tierras y puestos de trabajo

Acceso a tierras aptas para el cultivo

Prevención del riesgo de expropiación de terrenos propios

Entrega de un producto uniforme

\section{Desventajas para la empresa}

Incremento de los costos de transacción: negociación, supervisión, etc.

Desvío de insumos y préstamos por los agricultores a otros usos

Riesgo de no cumplir el contrato de parte de los agricultores: venta

a terceros, etc.

Riesgo de uso de insumos no permitidos

\section{Ventajas para los agricultores}

Acceso a un mercado seguro: venta asegurada y precios preestablecidos Acceso a asistencia técnica, que también es beneficiosa para otros cultivos

Utilización de insumos adquiridos para otros cultivos: químicos, capital etc.

Mejor aprovechamiento de la mano de obra

\section{Desventajas para los agricultores}

Riesgo de manipuleo de estándares de calidad y precios de parte de la empresa

Poca flexibilidad de la empresa para recibir la cosecha en el momento adecuado

Aceptación de condiciones que no son convenientes al productor: pago atrasado, etc.

\section{Utilización de las tierras en pocos cultivos}

Adaptado de CEPAL / GTZ / FAO, (7).

\section{Desafíos para los pequeños productores}

Como se ha mencionado anteriormente, el incentivo principal para que una empresa se decida por la agricultura por contrato es que sea la opción más rentable y segura para adquirir los volúmenes necesarios de cierto producto. Así, resulta obvio que una empresa busque trabajar con grandes productores, quienes, en comparación con los pequeños productores generan menos costos de transacción (costos administrativos que tienen mucho que ver con la elaboración de contactos, la supervisión, el acopio del producto, los pagos, etc.) (15).

Además, los pequeños productores tienen más restricciones de 
acceso al capital necesario para la producción y un nivel de educación más bajo, lo que implica un mayor esfuerzo en capacitación de parte de la empresa (18).

A pesar de que en general las condiciones son desfavorables, la literatura revela que bajo determinadas circunstancias resulta ventajoso para las empresas contratar a pequeños productores. Key y Runsten (15) describen un caso en México, en el cual una empresa contrató exitosamente a docenas de pequeños proveedores para la producción de brócoli y coliflor para exportación. Cálculos previos de la empresa demostraron que era más barato producir estas hortalizas en los huertos de los pequeños productores, cuyos costos eran de $55 \%$ en comparación con los de la empresa. La razón para ello era que los pequeños productores (1) comprometieron mano de obra más barata (pues usan mano de obra familiar a muy bajo costo de oportunidad y no pagaban seguro social a sus asalariados), (2) eran más eficientes en el seguimiento del cultivo y los trabajos efectuados (por su propio interés de ganar más) y (3) lograron acceder a terrenos adecuados a más bajo costo (gracias a convenios eficientes con sus vecinos del tipo sembrar "al partir", etc.). Sorprendentemente, en comparación con la producción de la propia empresa, los pequeños productores no sólo produjeron a un costo más bajo sino que lograron cosechas $20 \%$ más altas usando menos pesticidas. Esto pone en evidencia la gran ventaja del pequeño productor de efectuar un seguimiento óptimo a sus cultivos, detectando enfermedades en un estado temprano y aplicando pesticidas de manera minuciosa.

Otra ventaja de esta colaboración es que los pequeños productores aceptan condiciones que los grandes agricultores no aceptarían (16). Aunque genera una fuerte dependencia hacia la empresa, un contrato siempre es atractivo para el pequeño productor cuando éste logra superar las restricciones más fuertes para la producción (acceso a tecnología, información y crédito, etc.) y le proporciona más seguridad de ingreso. Igualmente importante es la modalidad de pago del producto. Por falta de liquidez, los pequeños productores prefieren asociarse con quienes no sólo les aseguren la compra del producto, sino que además les garanticen un pago a corto plazo. Por ejemplo, es por el pago continuo durante todo el año que los contratos entre pequeños productores de leche y la industria láctea son tan comunes. Sobre todo en las zonas de montaña, donde la producción de leche es una alternativa más segura que la siembra de cultivos, los pequeños productores bajo contrato son proveedores importantes de la industria láctea $(19,2)$. 


\section{Experiencias en la Agricultura por Contrato en Papa}

En gran parte del mundo la papa es un cultivo indispensable en la dieta humana. Por su costo relativamente bajo, la demanda en fresco es sustancial. Sin embargo, como los productores venden directamente su papa en el mercado, la agricultura por contrato no tiene importancia en este contexto. Diferente es la situación de quienes producen papa para el procesamiento. A este nivel, los contratos son primordiales para inducir un "mercado", garantizando el abastecimiento adecuado de la planta con la materia prima que requiere. Sin embargo, las siguientes experiencias documentadas demuestran que la colaboración entre pequeños productores y empresas de papa es muy restringida, por la preferencia de estas empresas de trabajar con los grandes productores.

\section{Caso "Canadá" La importancia de los costos de transacción}

Glover y Kusterer (12) describen el caso de la empresa McCain, que tiene una marcada preferencia por los grandes productores, alcanzando grandes volúmenes de abastecimiento con un bajo número de contratos. Aparte de sus contratos, McCain también sembró 7000 acres por cuenta propia, usando tecnología de punta para la producción de papa. Las economías de escala que se obtiene en ambos niveles de producción y procesamiento son primordiales para competir exitosamente en el mercado mundial de papas en tiras. Así, no sorprende que McCain haya desarrollado un gran poder de negociación -siendo el comprador principal en la zona de producción de papa- y determinado quiénes son sus proveedores y a qué precio compran la papa y bajo qué condiciones.

\section{Caso "Colombia" La importancia de la exclusividad del producto}

Restrepo (21) describe un caso interesante en Colombia, resaltando el hecho de que tanto los productores como la empresa procesadora tienden a romper el contrato si se presentan opciones más rentables a corto plazo que vender/comprar la papa de acuerdo al contrato. El problema principal en este caso es que la variedad de papa usada por la industria es una variedad común y bien cotizada también en los mercados. Por tanto, en épocas de escasez de esta variedad, cuando el precio era más alto que el prefijado en el contrato con la empresa, los productores preferían vender su papa en fresco. Por otro lado, en épocas de sobreoferta, cuando el precio se situaba muy por debajo del precio preestablecido con los proveedores, la empresa tendía a comprar su papa en el mercado mayorista. Es decir, al tener un mercado alternativo -debido a la falta de exclusividad del productolos contratos establecidos eran muy débiles en su función de predeterminar las transacciones de papa entre productores y la empresa. 


\section{Caso "Tailandia" \\ La importancia de las asociaciones de productores}

Örnberg (20) pone énfasis en la importancia de las asociaciones de productores en Tailandia como punto de partida para la producción de papa bajo contrato. Por falta de grandes productores, en los años '80, varias empresas de procesamiento de papa empezaron a formalizar su colaboración con asociaciones de productores existentes desde los años '60, que fueron formadas para acceder a semilla de papa de alta calidad importada por el gobierno y distribuida sólo a miembros oficiales de una asociación. La existencia de estas asociaciones facilitó a las empresas ahorrar costos de transacción en el acopio de los volúmenes requeridos de papa, mientras que los productores aprovecharon para tener un mercado seguro para su papa. Es más, el aumento de la competencia entre las empresas por la compra de papa fortaleció continuamente el poder de negociación de estas asociaciones desde los años '90, implicando no sólo mejores precios sino también mejor acceso a insumos y servicios financieros (provisión de fertilizantes y pesticidas y créditos a más bajo costo, etc.).

Según Örnberg (20) el funcionamiento de las asociaciones de productores en Tailandia dependió principalmente de tres factores: (1) la existencia de un problema o de una oportunidad aprovechada y resuelta sólo por una agrupación de productores, (2) un buen liderazgo de la asociación y (3) un contexto político favorable. En resumen, fueron claramente las ventajas económicas por cada socio (en este caso el acceso a semilla certificada y servicios) las que motivaron su participación en una asociación, y no un compromiso social o una preocupación general por el bienestar de los demás socios, como lo mencionan otros estudios (10).

\section{Caso "Perú"}

\section{La importancia de aprovechar la creciente demanda por hojuelas de papa}

\section{Contexto para las empresas que procesan papa}

La papa es un cultivo con mucha tradición en la cultura peruana. Aunque en las últimas décadas el consumo per capita ha bajado en función del aumento de la población en las ciudades, con otro estilo de vida y hábitos de consumo donde el arroz, pan y fideos han ganado importancia, este tubérculo mantiene un rol sustancial en la dieta nacional (13). Esencialmente en las alturas de los Andes (sierra), la papa sigue siendo el alimento principal y muchas veces la fuente de ingreso más importante para los agricultores.

Los agricultores de la sierra tienen la ventaja de que su cultivo de papa, condicionado por la época de lluvias (noviembre hasta mayo), alterna con el de la costa (abril hasta octubre). 
En este sentido, el abastecimiento equilibrado del mercado es la consecuencia de la provisión de papas de ambas zonas. Sin embargo, existe una fuerte fluctuación en la disponibilidad de variedades que sólo se pueden cultivar en la sierra o en la costa (Figura 1).

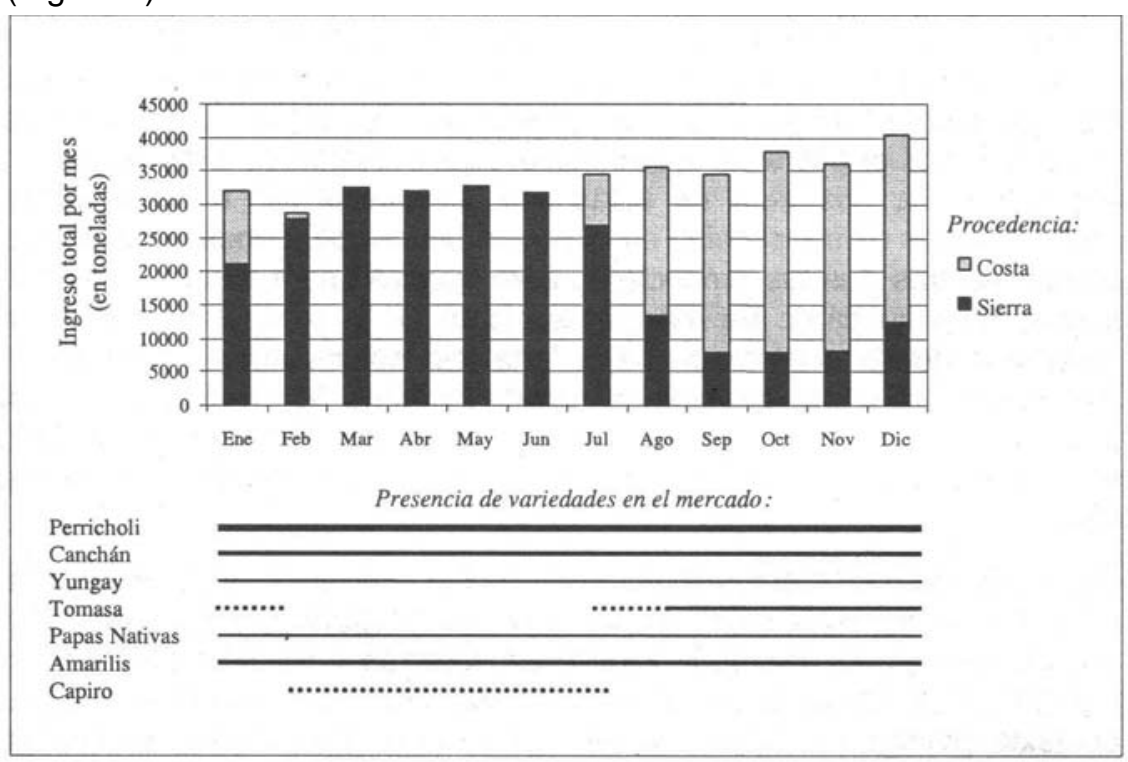

Figura 1. Ingreso promedio de papa al mercado mayorista en Lima (1994-1996)

En base a Cevasco et al. (6)

\section{La historia de la producción de papa para hojuelas}

En el Perú, la producción de hojuelas de papa empezó a nivel artesanal. A partir de los años 70, tres empresas producían este producto para el mercado nacional. Las variedades con las mejores propiedades de fritura eran Ticahuasi y Mariva, variedades mejoradas que se conseguían en el mercado mayorista. La creciente demanda de hojuelas generó una ampliación de la producción de estas variedades. A la vez, la competencia entre las empresas por abastecerse de estas variedades indujo a los intermediarios a especializarse en su compra en la sierra para luego venderla a las empresas. En 1988, la empresa Karinto S.A. estableció los primeros contactos directos con los productores de papa con el fin de mejorar su adquisición de materia prima. La zona de producción escogida fue el valle interandino del Mantaro, a 7 horas de distancia de Lima, con una altitud de 3300 metros, donde la producción de papa siempre ha sido una actividad principal, sobre todo en la producción de semilla para la costa (17).

En los años 80, la empresa Chipy dio un gran impulso a la producción 
de papa para hojuelas. Esta empresa posteriormente se convirtió en Savoy Brands, después de haber sido incorporada a la empresa internacional Frito Lays. Conjuntamente con Karinto S.A. esta empresa rescató la variedad Diacol Capiro en el Perú, una variedad colombiana traída al valle del Mantaro en los años 70 por un funcionario del Centro Internacional de la Papa (CIP) y que fue sembrada en las chacras de unos grandes productores. Sin embargo, por desconocimiento de parte de los consumidores, la Capiro no había sido aceptada en el mercado, desapareciendo enseguida de las chacras de los grandes productores. Fueron más bien los pequeños productores quienes la sembraron en sus propias chacras después de haber recibido la semilla como parte de pago de sus jornales trabajados en las chacras de estos grandes productores, apreciando esta variedad por su buen sabor y rendimiento, su fácil almacenaje y por ser relativamente tolerante a las plagas y enfermedades en comparación con las demás variedades que tenían.

En los últimos años de la década de los '80, Snacks América Latina S.R.L. empezó a producir semilla básica de Capiro bajo convenios con productores independientes, el INIA (Instituto Nacional de Investigación Agraria) y la ONG Fovida con el fin de aumentar la producción de hojuelas en base a esta variedad. En consecuencia, la siembra de Capiro aumentó drásticamente en el valle de Mantaro. En la campaña 1993-94, la empresa comenzó a establecer sus primeros acuerdos con productores que sembraban más de 5 hectáreas de Capiro. En ese momento se "quedaron fuera" los pequeños productores que antes podían vender su papa a esta empresa mediante acopladores autorizados.

No obstante, estos pequeños productores pudieron aprovechar la coyuntura: se formaron otras empresas que buscaban Capiro para procesamiento. En el año 1997, una de ellas, Bocaditos Nacionales S.A, estableció su propio convenio con un conjunto de 16 pequeños productores que se comprometieron a vender la cosecha de sus 12 hectáreas de Capiro exclusivamente a la empresa, que les brindó créditos sin intereses en insumos agrícolas para la siembra. El precio de la papa se fijaba en la cosecha, de acuerdo al precio del producto en el mercado mayorista; los préstamos fueron devueltos con el pago de la cosecha. Esta colaboración fue muy ventajosa para estos pequeños productores porque constituyó un negocio seguro que además trajo otros beneficios: la empresa brindó asesoramiento técnico y compró las cosechas en la chacra encargándose del transporte, lo que facilitó al productor la programación de su cosecha y el despacho inmediato. Para asegurar el abastecimiento de su planta y estar presente en el valle del Mantaro, esta misma empresa paralelamente sembró 10 hectáreas de Capiro en la campaña agrícola 1998-1999. Pese a que el clima fue favorable durante esta campaña y que muchos productores sembraron Capiro, la empresa se convenció que era más barato establecer convenios con los productores que sembrarla con fondos propios.

Posteriormente, estos convenios también fueron dejados de lado debido a que la disponibilidad de semilla y la expectativa de recibir 
precios altos causaron una sobreoferta de esta variedad. En este contexto resultó más rentable para las pequeñas empresas comprar la papa a través de intermediarios (acopiadores), que se encargan de abastecer a las plantas comprando la papa directamente en la chacra o incluso en el mercado mayorista en épocas de excedentes. Por no tener un contrato con Snacks América Latina S.R.L., muchos pequeños productores enfrentaron precios muy bajos, de lo cual se aprovecharon los intermediarios y las pequeñas empresas. De hecho, estas empresas consiguieron su materia prima -de similar calidadmucho más barata que su gran competidor Snacks América Latina S.R.L., que pagaba precios altos a sus proveedores de acuerdo al contrato.

Cabe mencionar que por ser una alternativa rentable $y$ aparentemente segura, la siembra de Capiro también fue promovida por varias ONGs, que brindaron capacitación y créditos a los productores en los últimos años de los '90. Sin embargo, como las pequeñas empresas perdieron interés en colaborar directamente con los productores, estas iniciativas cesaron pronto. Más estabilidad logró la intervención de la ONG Fovida, quien obtuvo desde 1999 contratos colectivos con la empresa Snacks América Latina S.R.L., con la expectativa de organizar a los pequeños productores en futuras empresas para superar las limitaciones de escala y orientarse hacia mercados más dinámicos. Para garantizar la calidad exigida por Snacks América Latina S.R.L., Fovida empezó a transferir capacidades organizativas, técnico-productivas y de comercialización, y encargó a otra ONG otorgar préstamos financieros a los productores.

\section{Situación Actual de la Colaboración entre Productores y Empresas}

En la actualidad, el mercado nacional es dominado por Snacks América Latina S.R.L. Esta empresa procesa alrededor de 160 toneladas de papa por semana, en base a la papa que proviene de la costa (Tomasa) y de la sierra (Capiro) (Figura 1). Este abastecimiento es muy grande si se compara con las demás empresas del mercado (9). En el valle del Mantaro, la empresa tiene casi 20 contratos para asegurar la siembra de Capiro en alrededor de 300 hectáreas.

Debido a su línea continua de procesamiento de hojuelas, Snacks América Latina S.R.L. exige una mayor calidad de papa que sus competidores. Es por eso que garantiza precios más altos a sus proveedores (alrededor de 30 centavos de dólar por $\mathrm{kg}$ ). De allí que la rentabilidad de la producción de Capiro depende estrechamente de cuánta papa logra vender un productor a Snacks América Latina S.R.L., ya que las otras empresas suelen pagar precios mucho más bajos -hasta la mitad-siempre tomando como referencia los precios del mercado mayorista (Tabla 2). 
Tabla 2. Características y condiciones de compra de empresas que procesan hojuelas de papa

\begin{tabular}{|c|c|c|c|}
\hline Empresa & Snacks América Latina S.R.L & Laurel S.A & Otras 25 empresas \\
\hline \multicolumn{4}{|l|}{ Calidad requerida } \\
\hline $\begin{array}{l}\text { - Nivel de azúcares } \\
\text { - Condiciones físicas }\end{array}$ & muy alta & regular & regular/baja \\
\hline Producción semanal & 160 toneladas & 24 toneladas & 150 toneladas \\
\hline Nivel de tecnología & muy alto (línea continua) & regular & bajo \\
\hline Modalidad de trabajo & contratos, muestra de fritura & muestra de fritura & sin muestra de fritura \\
\hline Precio & muy alto (preestablecido) & precio mayorista y calidad & precio mayorista \\
\hline Pago & 15 días después entrega & 15 días después entrega & variable \\
\hline Tamaño de tubérculos & $5-10 \mathrm{~cm}$ & 1ra:6-9cm,2da:3-5cm & en general $5-10 \mathrm{~cm}$ \\
\hline Exigencias especiales & buena selección, mallas 70kg & & \\
\hline
\end{tabular}


Debido al alto precio pagado por Snacks América Latina S.R.L., es un afiliado muy importante para los productores de papa. Sin embargo, por la política de la empresa, son ante todo los grandes productores los que han tenido el privilegio de suscribir un contrato directo con ésta, obligándose a sembrar varias hectáreas de Capiro. Este contrato garantiza un precio fijo a toda la papa cosechada en la fecha programada que cumpla con los requerimientos de calidad establecidos: (a) tamaño del tubérculo entre 5 y $10 \mathrm{~cm}$., sin daños y limpio, (b) que no se "queme" (bajo nivel de azúcares reductores) y (c) que sea transportada en mallas rojas de $70 \mathrm{Kg}$. (Cuadro 2).

La "prueba de fuego" para cada productor es la fritura de una muestra de $10 \mathrm{Kg}$. que se envía unos días antes de la cosecha para averiguar si la papa tiene un bajo nivel en azúcares. Si esta muestra es aprobada, se planifica la cosecha para una fecha determinada. Un representante de la empresa suele estar presente para supervisar la cosecha, la buena selección y el embalaje de la papa. El propio agricultor se encarga de contratar a un transportista para que lleve su cosecha a la planta en Lima. Otra prueba de $300 \mathrm{Kg}$. es tomada en ese instante, cuando la papa llega a la planta, para reverificar la calidad de la papa. Es esta última prueba la que determina si la papa ingresa o no a la fábrica -independientemente de la primera pruebaya que no sólo se evalúa la fritura, sino también el aspecto físico de los tubérculos. En la mayoría de casos estas cargas son aceptadas, pero suele ocurrir que después de haberse aprobado la primera muestra, se ha rechazado toda la carga por no aprobar la segunda. Es obvio que tal experiencia causa al productor una frustración enorme en vez de ganar "buen dinero", este rechazo implica buscar intempestivamente otro comprador, que de hecho pagará un precio muy por debajo del esperado. En ese momento el productor se encuentra realmente en una trampa porque no sabe dónde vender su papa, además de estar bajo presión de parte del transportista quien quiere que se descargue el camión pronto para recibir su pago. Algunos productores mencionan que en esos momentos aparecen agentes de otras empresas en las puertas de Snacks América Latina S.R.L. "esperando como águilas" para apropiarse de la carga rechazada. Estas empresas se ven favorecidas pues consiguen a bajo precio materia prima limpia y bien seleccionada dentro de sus estándares de fritura. Ello constituye una gran ventaja para estas empresas que, por exigir menor calidad, tienen mayor flexibilidad en la compra de su materia prima, con lo cual venden hojuelas de papa de menor calidad pero a precios más competitivos. En este contexto, estas empresas pequeñas tienen gran poder de negociación porque vender la papa rechazada en el mercado mayorista tampoco es una alternativa, como señala un productor de papa por su propia experiencia: "Cuando los mayoristas ven la papa en las mallas especiales que exige Snacks América Latina S.R.L. saben que se trata de papa rechazada y eso les sirve para bajar el precio a un nivel mínimo". 


\section{Experiencias de las Asociaciones de Productores en el Valle del Mantaro}

\section{Motivos para agrupar pequeños y medianos productores}

Como mencionáramos anteriormente, la empresa Snacks América Latina S.R.L. suele trabajar con productores medianos y grandes, que tienen mucha experiencia en la siembra de papa y son capaces de sembrar un mínimo de 5 a 10 hectáreas. De parte de la empresa reciben capacitación técnica $y$, por tener un contrato, consiguen créditos con más facilidad mediante terceros (caja municipal, bancos locales, ONGs, etc.).

Los pequeños productores no califican para ser proveedores directos de la empresa, salvo que se asocien para suscribir un solo contrato con la empresa y que constituyan una entidad seria y formal que garantice la siembra con Capiro en la cantidad mínima requerida de hectáreas. Sin embargo, este reto es muy grande porque estos productores enfrentan un conjunto de restricciones que no son favorables: (1) falta de capital para invertir en la producción mínima requerida, (2) falta de estatus legal para facturar a la empresa, (3) falta de conocimientos para producir una papa de alta calidad, (4) falta de poder de negociación con proveedores de insumos para abaratar sus costos (5). Además, el fracaso del modelo cooperativo de la reforma agraria en la década del 70 , ha generado desconfianza hacia las organizaciones entre los productores peruanos, por lo que existe resistencia a cualquier forma de asociación. Es por ello que la intervención pionera de Fovida ha sido crucial para respaldar la formación de 3 asociaciones de productores de papa en el valle del Mantaro. Un trabajo similar se viene haciendo en Ayacucho, donde la ONG Care ha empezado a agrupar productores pequeños para producir Capiro para Snacks América Latina S.R.L. bajo convenios (3).

\section{Modalidades de colaboración entre los productores, Fovida y Snacks América Latina S.R.L.}

Para participar en el proyecto de Fovida se exigía a los pequeños productores tener experiencia en la producción de papa y voluntad de trabajar organizadamente, así como aceptar los compromisos establecidos en un convenio de cooperación entre Fovida y la "asociación en formación". Considerando las limitadas alternativas de producción, la idea de Fovida de sembrar papa para la agroindustria era muy atractiva para los productores. Fovida se comprometió a brindar semilla de calidad, capacitación técnica para asegurar un buen manejo del cultivo y capacitación en materia organizativa y comercial. Además, aseguró la comercialización de papa bajo un contrato entre Snacks América Latina S.R.L. y Fovida. Para acceder al capital necesario para la siembra, Fovida suscribió un convenio con una ONG financiera, el Grupo Consultivo Para el Desarrollo (GCOD), brindando préstamos individuales de 2500 dólares a cada productor, en base a fondos especiales del proyecto, aprobados por Fovida a 
través del Fondo Contravalor Perú-Canadá. Para obtener tal crédito se requería la garantía de algún objeto de valor (carro, tractor etc.) y/o del título de propiedad del terreno, propio o de terceros. El interés mensual en dólares americanos era de $2 \%$ a $2.5 \%$, que es un interés común en la zona. Este crédito también fue usado para comprar semilla de calidad producida por Fovida, que puso a disposición del proyecto dos invernaderos y un sistema de almacenamiento antiáfido, así como la conducción y capital de trabajo que garantizaba su operación.

La facturación de la papa a Snacks América Latina S.R.L. fue hecha por Fovida porque los productores todavía no tenían estatus legal. Las demás ventas de papa, de menor calidad, así como su liquidación, estaban bajo responsabilidad de los propios productores. La devolución del préstamo no estaba directamente vinculada a la liquidación de la venta de papa sino al contrato de financiamiento suscrito con GCOD, que fijaba un periodo pre establecido para el reembolso.

\section{Experiencias de la campaña 1999-2000}

En el primer año de intervención del proyecto de Fovida, correspondiente a la campaña 1999-2000, participaron un conjunto de 13 productores que sembraron 1 hectárea de Capiro cada uno. Gracias al clima favorable para la producción de papa, esta campaña fue muy exitosa en términos de cantidad y calidad. La mayoría de productores (9) colocaron su papa en Snacks América Latina S.R.L. logrando una buena ganancia debido al alto precio pagado, 0.85 nuevos soles por kilogramo, y al buen rendimiento. Sólo dos productores tuvieron problemas: en uno, la rentabilidad fue cercana a cero y en el otro fue negativa debido a problemas de manejo que se tradujeron en bajos rendimientos y calidad. Los demás lograron una rentabilidad entre 20\% y $70 \%$ (Figura 2). Si se tiene en cuenta que los demás pequeños productores del valle del Mantaro experimentaron un precio muy bajo por su papa común como consecuencia de la sobre producción, 0.20 nuevos soles en chacra, la siembra de Capiro bajo contrato fue un verdadero éxito para los productores asociados. En consecuencia, los servicios brindados por Fovida fueron altamente apreciados, sobre todo la capacitación referente a la fertilización adecuada del cultivo con nitrógeno y fósforo, lo que tiene gran influencia sobre el nivel de azúcares en los tubérculos y la calidad de fritura. 


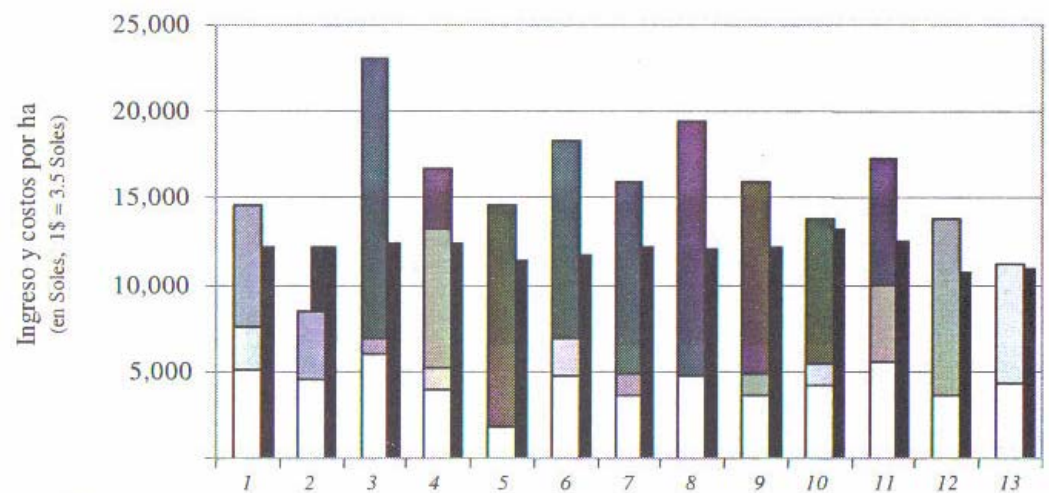

Ingresos

-1 Snacks América Latina S.R.L.

口 Otra industria

ㅁ Intermediarios

․ Semilla

Costos

$39 \%$ Insumos

$10 \%$ Maquinaria agrícola

$2 \%$ Yunta

$19 \%$ Mano de obra

$11 \%$ Fletes, mallas y otros

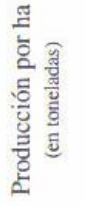

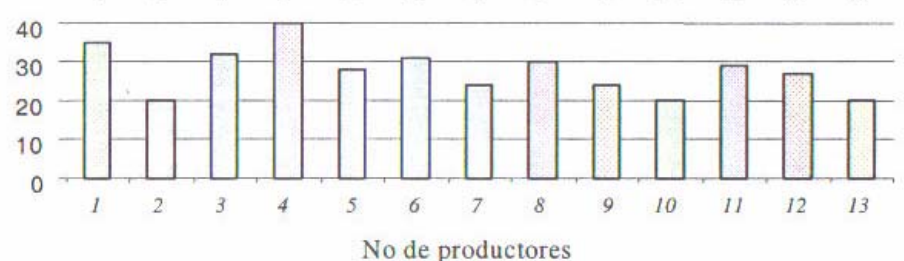

Terreno

$12 \%$ Intereses

Figura 2. Ingresos y costos en la siembra de Capiro de los 13 productores de la asociación de Fovida en la campaña 1999-2000.

En base de datos de Fovida 
Debido a la alta rentabilidad alcanzada durante esta campaña, el proyecto pudo ampliar su cobertura al $70 \%$ de lo previsto en el diseño del proyecto, buscando la participación de un total de 45 agricultores. Los interesados en participar en la siguiente campaña eran ya 32 productores. El nuevo contrato entre Fovida y Snacks América Latina S.R.L. fue ampliado, por tanto, a 32 hectáreas. Fovida ayudó a formar dos asociaciones más para agrupar a los nuevos productores en el proyecto, de acuerdo a la ubicación de sus chacras.

\section{Experiencias en la campaña 2000-2001}

Esta campaña, sin embargo, fue muy difícil. La ausencia de Iluvia provocó una fuerte sequía y varias heladas. La destrucción de un canal de riego en una asociación empeoró la situación. Por tanto, los factores climáticos adversos bajaron drásticamente la calidad de la papa, debido a altos niveles de azúcares en los tubérculos, y los rendimientos disminuyeron hasta $40 \%$ en comparación con la campaña anterior. Así, el problema principal no fue el precio pagado por las demás empresas para la papa rechazada, ya que ante la escasez de Capiro estas empresas se vieron forzadas a pagar un precio mayor que la campaña anterior (Figura 3).

Pese a la "mala experiencia" que significó para la mayoría de los productores -de los cuales 19 eran nuevos- las pérdidas sufridas en esta campaña, 29 de 32 han vuelto a participar en el proyecto para la siguiente campaña. Creemos que tres razones los motivan a seguir participando en el proyecto: (1) los precios más altos recibidos por Capiro en comparación con las variedades comunes, por lo que se espera que esta variedad genere una mejor rentabilidad con condiciones climáticas regulares, (2) la falta de liquidez y de alternativas de producción, que implica que la resiembra de Capiro es la opción más conveniente para no comprar semilla (3) la ventaja de ahorrar entre $5 \%$ y $12 \%$ en compras colectivas de insumos, lo que significa un incentivo importante para estar asociados y seguir sembrando Capiro.

Otro resultado de esta mala campaña ha sido que la mayoría de los productores no ha devuelto el préstamo otorgado por GCOD; casi un año después, sólo uno de los 32 productores ha devuelto la totalidad del préstamo. Otros han devuelto una parte, pero la gran mayoría hasta hoy se resiste a pagar. Una causa para esta alta tasa de morosidad se debe al proceso de reorganización del Fondo Contravalor Perú-Canadá, entidad que suministró los préstamos a los productores. En la actualidad existe muy poca comunicación entre las contrapartes y la población beneficiaría, lo que impide la toma de decisiones de GCOD para exigir el reembolso de los prestamos.

Pareciera que la mayoría de productores está aprovechando esta situación para no devolver sus préstamos. El análisis económico demuestra que este "negocio" de no pagar el préstamo resultó altamente beneficioso para los agricultores. 


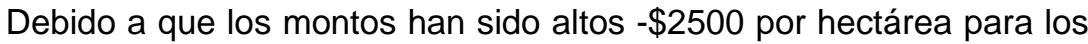
agricultores "nuevos" y \$ 1750 para los agricultores de la 2da campaña que sembraron dos hectáreas- los productores lograron una ganancia neta mínima de alrededor de 5000 nuevos soles por hectárea (Figura 3). Como un nuevo crédito siempre es un incentivo importante para devolver el préstamo anterior, y debido a que el proyecto ya no proporcionará créditos para la campaña 2001-2002, es muy probable que la mayoría de los productores nunca devuelvan sus préstamos, aún cuando obtengan una buena ganancia en la próxima campaña.

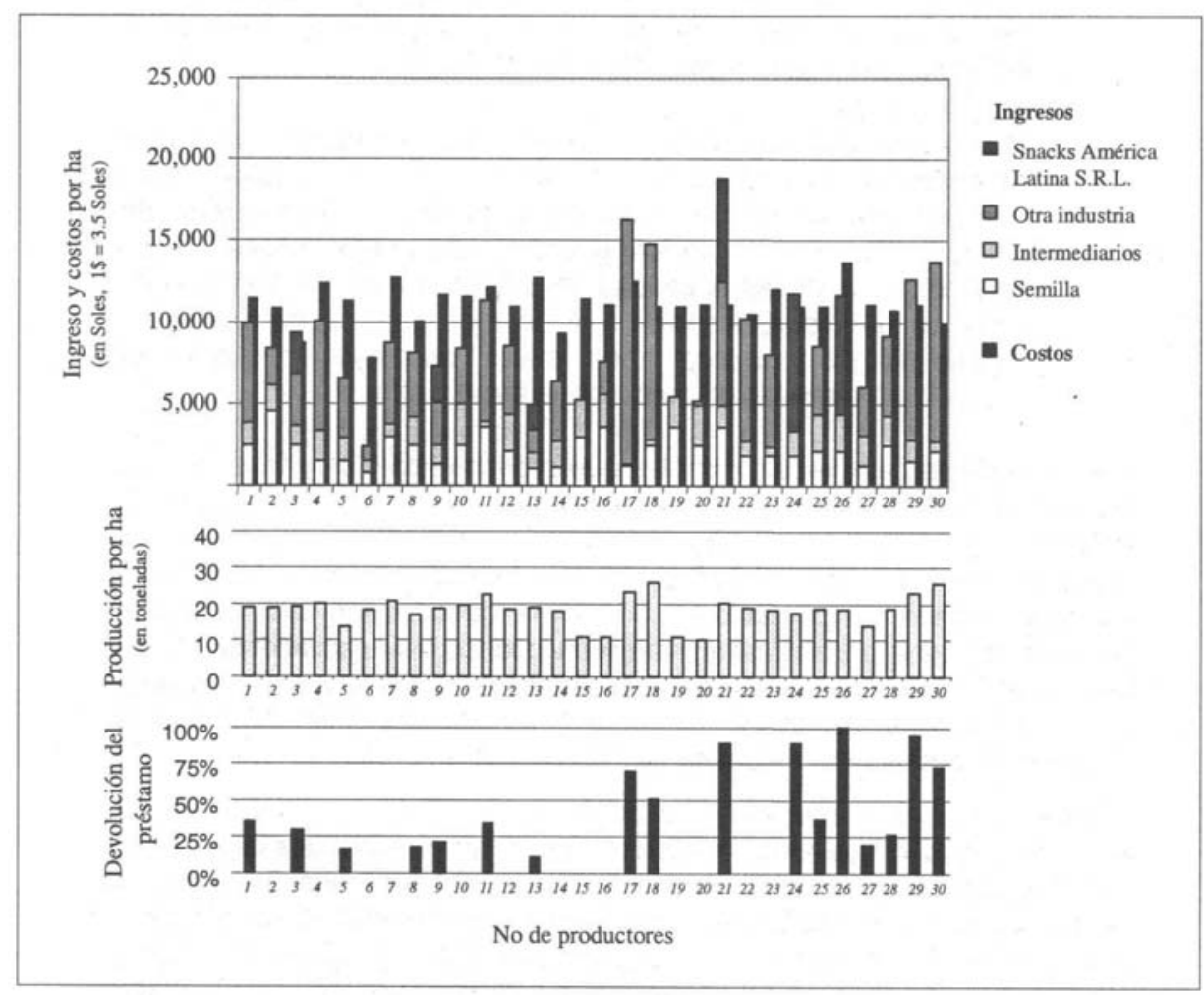

Figura 3. Ingresos y costos en la siembra de Capiro de 30 productores de la asociación de Fovida en la campaña 2000-2001.

En base a datos de Fovida (datos de 2 productores no disponibles) (9). 


\section{Discusión y Conclusiones}

Los casos en la literatura y la experiencia de la Sierra Central del Perú indican que por lo menos la industria que procesa hojuelas y tiras (a la francesa) prefiere colaborar con grandes en vez de pequeños productores. Estas empresas obtienen dos ventajas principales de su colaboración con los grandes productores:

- Costos de transacción más bajos: (1) el número de visitas de seguimiento es menor por trabajar con un número reducido de grandes productores, (2) el acceso a los fundos grandes es más fácil y (3) la empresa requiere menos inversión en trabajos de extensión para garantizar un buen manejo del cultivo.

- Más seguridad de conseguir papa de alta calidad: (1) el gran productor tiene un mejor nivel de educación y más experiencia en el manejo del cultivo para alcanzar un producto uniforme y de alta calidad, (2) en los fundos grandes hay mejor acceso a los insumos que elevan la calidad del producto (semilla, suelo, riego, insumos químicos, tecnología y capital) y (3) la capacidad de asumir riesgos y superar años "malos" es mayor, lo que brinda estabilidad a la relación comercial a largo plazo.

Para las grandes empresas formales que produce hojuelas y tiras de papa bajo contrato, el pequeño productor parece ser solamente una "solución de emergencia", cuando no hay suficientes productores grandes que abastezcan la planta. Sin embargo, en estos tiempos de escasez de oferta, las asociaciones de pequeños productores puedan ser una alternativa interesante para la agroindustria, siempre y cuando las asociaciones (1) son bien organizadas (implicando costos de transacción bajos para la empresa) y (2) reciben capacitación técnica de parte de una institución de desarrollo (implicando un producto de buena calidad para la empresa).

¿Estas asociaciones de pequeños productores van a seguir competitivas, asumiendo que los grandes productores van a ser incentivados de expandir su producción de papa? Este estudio no puede responder esta pregunta; de hecho dependerá mucho de las capacidades que desarrollan los pequeños productores en el futuro de organizarse bien y alcanzar buenos rendimientos de papa de buena calidad. En el caso del Perú, cierto es que los grandes productores también enfrentan problemas de competitividad cuando expanden su producción con terrenos alquilados; la supervisión adicional de terrenos alejados trae considerables costos adicionales.

Ya que es muy probable que los grandes productores por sí solos no logren producir suficiente papa para abastecer a la agroindustria durante los próximos años, debido al crecimiento rápido de la demanda, el reto para los pequeños productores debe ser explotar esta oportunidad organizándose en asociaciones de productores. 
Estas asociaciones y las experiencias adquiridas serán un "capital" importante que les posibilitará, más adelante, reorientar su producción y sus mecanismos de colaboración hacia nichos de mercado en los cuales ellos son más competitivos que los grandes. De hecho la competitividad de los pequeños productores es mayor en oportunidades de negocio que tienen las siguientes características:

- El seguimiento del cultivo tiene un efecto importante sobre la rentabilidad y la calidad de la producción: Los pequeños productores pueden prevenir y luchar contra las plagas con más eficiencia disponiendo más tiempo para cuidar a sus cultivos de más cerca.

- La mano de obra es más importante que la tecnología y el capital: Por la disponibilidad o mejor acceso a mano de obra a bajo costo, los pequeños productores tienen ventajas en producir papa que requiere un uso más intensivo de mano de obra en vez de tecnología sofisticada, como por ejemplo "papas cocktail" o papas orgánicas, donde el manejo y la selección de papa requiere mucha mano de obra.

- Las condiciones de producción requeridas ofrecen una ventaja natural al pequeño productor: Los pequeños productores de la Sierra puedan aprovechar de producir y comercializar variedades de papa nativa que son especialmente adaptadas a su zona de producción.

- Las condiciones de producción del pequeño productor se reflejan en la comercialización del producto final: El pequeño productor tiene una ventaja exclusiva frente a los grandes productores cuando el producto final explícitamente enfatiza aspectos productivos o sociales del pequeño productor, por ejemplo mencionando en la etiqueta que el producto "ayuda a generar ingresos en zonas pobres de la Sierra" etc. Bajo esta estrategia las papas o sus derivados pueden orientarse hacia el mercado equitativo o "fair trade".

La creciente demanda para productos orgánicos, equitativos, exóticos y étnicos, etc. en los países desarrollados abre nuevas puertas para la comercialización de productos en base de papa, donde los pequeños productores puedan tener ventajas. Así, la exportación exitosa de mini papas amarillas (criollas) desde Colombia y Ecuador a Ios EE.UU. y Japón como bocaditos subraya la emergencia de estas nuevas oportunidades de mercado.

Sin embargo, resulta sustancial el apoyo profesional externo para ayudar a los pequeños productores de vincularse exitosamente con el mercado. Procesos participativos que fomentan un buen nivel organizativo de los productores pequeños con un fuerte enfoque de marketing es fundamental - si no se corre el riesgo común de que el intento de formar una asociación se quiebre desde sus inicios por falta de experiencia empresarial y una perspectiva falsa sobre cómo debe funcionar una asociación (5). En todo caso, las instituciones que 
lideran tales procesos deberán tener mucho cuidado de no provocar situaciones en las cuales los productores se aprovechen, por mal manejo de fondos para créditos, infraestructura e insumos etc., erosionando la ética y la confianza entre las personas involucradas dos factores pocos estudiados, pero sumamente importantes para lograr un desarrollo rural sostenible.

\section{Referencias Bibliográficas}

1. Apoyo. 1996. Situación y perspectivas del sector agrícola. Apoyo. Lima, Perú.

2. Bernet, T., M. Tapia. 1999. Análisis de los sistemas de producción de la microcuenca de la Encañada - Cajamarca. Documento de trabajo No. 1999-2. Centro Internacional de la Papa (CIP), Lima, Perú.

3. Cajamarca, O. 2001. Producción y comercialización de papa Capiro y nativa en Acordo-Ayacucho. Informe Proyecto Altura, Care, Lima, Perú.

4. Caro, C. 1999. La articulación de la agroindustria y la pequeña agricultura de los valles de Chao y Virú. Seminario Permanente de Investigación Agraria (SEPIA) VIII, Lima, Perú. 117-154.

5. Cayota, S. 1996. La gestión empresarial en los agronegocios de pequeños productores. Ruralter, No. 15. 49-61.

6. Cevasco, J.C., P. Figueroa, E. Méndez, L. Terrones, F. Villasante. 1999. Determinantes del bajo nivel de desarrollo de la agroindustria de papa en el Perú y estudio de prefactibilidad para la instalación de una planta de papa prefrita congelada. Tesis. Escuela de Administración de Negocios para Graduados (ESAN), Lima, Perú.

7. CEPAL / GTZ / FAO. 1998. Agroindustria y pequeña agricultura: vínculos, potencialidades y oportunidades comerciales. Naciones Unidas. Santiago de Chile, Chile.

8. Eaton, C., A. Shepherd. 2001. Contract farming - partnerships for growth. FAO Agricultural Services Bulletin 145. Rome, Italy.

9. Fovida, 2001. Informe de cierre del proyecto "Producción y comercialización de papa consumo y semilla para la agroindustria". Fondo para la Vida (Fovida), Lima, Perú.

10. Garforth, C., S. Paiboon. 1996. Who benefits from agricultural extensión? "Training and visit" and the role of rural people's organisations in the upper north of Thailand. In: Parnwell M. J. (ed.). Uneven development in Thailand, Avebury Aldershot, England. 
11. Glover, D. 1987. Increasing the benefits to smallholders from contract farming: problems for farmers' organizations and policy makers. World Development, Vol. 15 No. 4: 441-448.

12. Glover, D., K. Kusterer. 1990. Small farmers big business - contract farming and rural development. The Macmillan Press. London, England.

13. Herrera, J., G. Scott, N. Espinola, W. Amorós, M. Ato. 1994. Perspectivas para el desarrollo agroindustrial de la papa. Debate Agrario 19, Lima, Perú, 67-86.

14. Horton, D. 1987. Potatoes - production, marketing, and programs for developing countries. Westview Press. London, England.

15. Key, N., D. Runsten. 1999. Contract farming, smallholders, and rural development in Latin America: the organization of agroprocessing firms and the scale of outgrower production. World Development, Vol. 27 No. 2:381-401.

16. Little, P., M. Watts. 1994. Living under contract: contract farming and agrarian transformation in sub-saharan África. University of Wisconsin Press, Madison, USA.

17. Mayer, E. 1979. Land use in the Andes - ecology and agriculture in the Mantaro Valley of Perú, with special reference to potatoes. International Potato Center (CIP), Lima, Perú.

18. Minot, N. 1986. Contract farming and its effect on small farmers in less developed countries. Working Paper No. 31, Michigan State University International Development Papers. East Leasing, Michigan, USA.

19. Mosley, P. 1986. Marketing systems and income distributions: the case of milk producers in highland Perú. Food Research Institute Studies 18 No. 3:275-291.

20. Örnberg, L. 1999. Potato farmers' organization in Thailand: a discussion on the prerequisites of the formation and survival of farmerorganizations. Paper presented at the 7th International Conference on Thai Studies, Amsterdam, The Netherlands, July 4-8, 1999.

21. Restrepo, J. 1987. An analysis of the contractual relations between Potato growers and processors in Columbia. Thesis at Cornell University, Rhode Island, USA.

22. Scott, G., L. Maldonado, V. Suárez. 2001. Nuevos senderos de la agroindustria de la papa. Revista Latinoamericana de la Papa Volumen Especial 'Agroindustria de la Papa en América Latina': 1-20. 